\title{
Unilateral exophthalmos
}

\section{Aetiological study of 85 cases}

\author{
HANNA-SAMIR ZAKHARIA, KEVORK ASDOURIAN, AND \\ GAMILLE S. MATTA
}

From the Department of Ophthalmology, American University Medical Center, Beirut, Lebanon

Unilateral exophthalmos continues to intrigue and challenge the ophthalmologist. The condition has been described by many authors (O'Brien and Leinfelder, 1935; Dandy, I94I ; Drescher and Benedict, I950; Van Buren, Poppen, and Horrax, I957; Bullock and Reeves, I959; Schultz, Richards and Hamilton, I961 ; Moss, I962; Porterfield, I962; Jones, I962; Reese, r964; Pohjola, 1964; Palmer, I965; Silva, 1967; Smith, 1967) and the frequency of the different causes of this sign have varied according to the interest of the author and consequently the type of referrals. In reviewing 85 cases of unilateral exophthalmos seen at the American University Medical Center (AUMC), we considered that this constituted a good representative sample for the study of this condition for the following reasons:

(I) The AUMG is a general hospital, and patients with unilateral exophthalmos came not only from the ophthalmology service, but also from the rest of the hospital services. At least one ophthalmologist saw the latter cases in consultation.

(2) Only patients with unilateral exophthalmos of orbital origin were included. Unilateral ocular causes, such as axial high myopia or congenital glaucoma, were eliminated.

(3) Diagnosis of the aetiology was based on histopathological confirmation (I oo per cent. of neoplasms), and clinical, laboratory, and radiological evidence.

This series does not claim to reflect the relative incidence of orbital lesions, since many such proven cases may not produce significant exophthalmos or, as is frequently the case, they are bilateral.

\section{Material and methods}

The medical files of all patients with unilateral exophthalmos at AUMC were studied. Only cases with an exophthalmometric difference of at least $3 \mathrm{~mm}$. were included, the non-affected eye being normal by history and examination. All measurements were made with the Hertel exophthalmometer. Cases with bilateral involvement, even if they manifested such an exophthalmometric difference, were not considered. Cases which had the second eye involved at a later date were also rejected.

Routine investigation included a careful history and system review, a general and ophthalmological examination, thyroid studies, and blood counts. Radiological studies included $x$-rays of the orbit skull, and sinuses. Dye-contrast orbitography, internal carotid arteriography, tomography of the orbit, and special views of the optic foramina were performed when it was considered necessary. Phlebography (Krayenbühl, 1962), radiological exophthalmometry (Bogren and Tengroth, 1967), and ultrasonography (Gitter, Meyer, Goldberg, and Sarin, 1968) were not employed.

Received for publication October 18,1971

Address for reprints: Camille Matta, M.D., Department of Ophthalmology, American University Medical Center, Beirut, Lebanon 


\section{Results}

The patients were divided into six categories according to the aetiology. Table I shows the individual diagnosis in these categories and their distribution into three age groups.

Table I Incidence of aetiological diagnosis in the three age groups

Diagnostic group

I Neoplastic Meningioma

(36) Haemangioma

Dermoid cyst

Rhabdomyosarcoma

Metastatic carcinoma

Adenoid cystic carcinoma lac. gl.

Neuroblastoma, metastatic

Retinoblastoma with orbital extension

Epidermal cyst

Liposarcoma

Sarcoma, undifferentiated

Malignant melanoma with orbital extension

Cementifying fibroma, maxillary sinus

Reticulum cell sarcoma

Nasopharyngeal transitional cell carcinoma

Eosinophilic granuloma

Osteoma of ethmoid sinus

\begin{tabular}{lll}
\hline II & $\begin{array}{l}\text { Inflam- } \\
\text { matory (31) }\end{array}$ & $\begin{array}{l}\text { Orbital cellulitis/abscess } \\
\text { Mucocele/pyocele } \\
\text { Pseudotumour } \\
\text { Hydatid cyst }\end{array}$ \\
\hline III $\begin{array}{l}\text { Traumatic } \\
\text { (6) }\end{array}$ & Orbital haemorrhage
\end{tabular}

IV Endocrine (4)

V Vascular (3) Cavernous sinus thrombosis

Carotid-cavernous fistula

VI Unknown (5)

Total (85)
Age (yrs)

\begin{tabular}{lll}
\hline $0-15$ & $16-45$ & $46-79$ \\
\hline 2 & 2 & 2 \\
& 4 & 1 \\
& 3 & 1 \\
3 & & \\
I & I & I \\
& I & I
\end{tabular}

2

2

I

I

\begin{tabular}{ccc} 
& I & \\
& I & \\
I & I & \\
\hline 9 & I & \\
\hline 2 & 5 & 3 \\
I & 3 & 3 \\
\hline 4 & 1 & \\
\hline 0 & 2 & 2 \\
\hline 0 & 2 & 0 \\
0 & 1 & 0 \\
\hline 0 & 4 & 1 \\
\hline 31 & 37 & 17
\end{tabular}

\begin{tabular}{|c|c|}
\hline $\begin{array}{l}\text { Total } \\
\text { cases }\end{array}$ & $\begin{array}{l}\text { No. } \\
\text { patho- } \\
\text { logical }\end{array}$ \\
\hline 6 & 6 \\
\hline 5 & 5 \\
\hline 4 & 4 \\
\hline 3 & 3 \\
\hline 3 & 3 \\
\hline 2 & 2 \\
\hline 2 & 2 \\
\hline 2 & 2 \\
\hline I & I \\
\hline I & I \\
\hline $\mathbf{I}$ & $\mathbf{I}$ \\
\hline I & I \\
\hline $\mathbf{I}$ & $\mathbf{I}$ \\
\hline $\mathbf{I}$ & $\mathbf{I}$ \\
\hline I & I \\
\hline I & I \\
\hline I & I \\
\hline 14 & 3 \\
\hline 7 & 6 \\
\hline 7 & 5 \\
\hline 3 & 3 \\
\hline 6 & 0 \\
\hline 4 & I \\
\hline 2 & o \\
\hline I & 0 \\
\hline 5 & $\mathbf{I}$ \\
\hline 85 & 55 \\
\hline
\end{tabular}

NEOPLASTIC

This was the most common in our series ( 36 patients). It encompasses primary orbital tumours and metastatic malignancies, as well as secondary extension into the orbit from the globe, the cranium, the paranasal sinuses, and the nasopharynx. Haemangiomas were included in this group rather than in the vascular group. Histological confirmation was obtained in all cases.

\section{INFLAMMATORY}

There were $3^{I}$ patients in this group. Of fourteen cases of orbital cellulitis, three abscesses had to be evacuated, and their contents were studied pathologically and bacteriologically. 
All seven mucoceles were excised; histopathology on one is missing but the $x$-ray and operative findings were conclusive. Of the seven pseudotumours encountered, five were biopsied, and the other two manifested a typical clinical picture and responded dramatically to corticosteroids. The three cases of orbital hydatidosis have been reported in a previous paper (Baghdassarian and Zakharia, 1971).

TRAUMATIG

Six of our patients presented with a history of orbital trauma, unilateral proptosis of rapid onset, and normal $x$-rays of the orbit. The diagnosis of orbital haemorrhage secondary to trauma was supported in each case by at least three other hallmarks of periorbital and ocular trauma: eyelid swelling and ecchymosis, extraocular muscle paresis, subconjunctival haemorrhage, hyphaema, iritis with or without secondary glaucoma, iridoplegia, multiple sphincterotomies, iridodialysis, vitreous haemorrhage, and commotio retinae. The condition was self-limiting and the exophthalmos receded in I to 2 weeks.

\section{ENDOGRINE}

There were only four patients in this group. Two were hyperthyroid, one was hypothyroid, and the last was euthyroid. This last patient was a 55-year-old man with unilateral proptosis (exophthalmometric difference $13 \mathrm{~mm}$.) of 15 years' duration, normal visual acuity, and a normal fundus. A Berke-Krönlein exploratory orbitotomy was undertaken. No mass could be seen and biopsy of the hypertrophied orbital tissues revealed changes consistent with endocrine ophthalmopathy.

\section{VASGULAR}

Two out of seven patients with cavernous sinus thrombosis had unilateral exophthalmos One had staphylococcal septicaemia that subsided on adequate antibiotic therapy, though the patient continued to have some residual exophthalmos. The other patient had a complete internal carotid artery occlusion as demonstrated by arteriography, became comatose, and died. An interesting case in this category was a carotid-cavernous fistula after trauma that had closed spontaneously. Diagnosis was reached on the basis of the history, clinical findings, internal carotid arteriography, retrograde jugular venography, and orbital tomography.

\section{UNKNOWN}

Of the five patients in this group, three had unilateral exophthalmos $(3,5$, and $9 \mathrm{~mm}$. respectively) as the sole clinical findings. There was no palpable mass and the vision and fundus were normal. No abnormality could be found and no surgery was performed. These patients were lost to follow-up after discharge from the hospital.

The fourth patient, a 3 I-year-old woman with a $4 \mathrm{~mm}$. forward exophthalmos, visual acuity of counting fingers at $4 \mathrm{~m}$., papilloedema, and striae, had a mass indenting the $\stackrel{N}{\sigma}$ sclera, choroid, and retina, which could be seen by indirect ophthalmoscopy. The tentative diagnosis was a haemangioma of the muscle cone. Unfortunately, she refused surgery.

The last patient was a 79-year-old man with $14 \mathrm{~mm}$. exophthalmos, and a palpable orbital mass with evidence of intracranial extension by carotid arteriography and brain scan. Two successive generous biopsies showed "lymphoid tissue", and no tumour cells were identified. 


\section{Discussion}

The relative frequency of disease conditions causing unilateral exophthalmos varies in different series. Much depends on the medical speciality of the author and his method of collecting his cases. A neurosurgeon like Dandy (I94I) mostly has referrals of tumours of neural origin invading the orbit secondarily. Bullock and Reeves (1959) present a radiological review of 245 cases of unilateral exophthalmos in which mucocele appears to be the most common cause. Drescher and Benedict (1950), with 177 cases, Schultz and others (1961) with 59 cases, and Moss (1962) with 230 cases share the view that endocrine ophthalmopathy ranks foremost in asymmetric proptosis. Some of these may have been bilateral but with unequal proptosis! More recently, Silva (1967) reported a series of 230 consecutive cases of unilateral exophthalmos in which he listed pseudotumour as the commonest cause followed closely by mucocele. Palmer (1965) quoted eight series, making a total of 2,073 cases of unilateral exophthalmos, of which orbital tumours constituted the bulk. Unfortunately, he included a series of 877 eyes for Reese which actually formed a histopathological review of orbital lesions irrespective of the presence of exophthalmos or its unilaterality.

In our series, the majority of cases were of the neoplastic group. This is in agreement with most other series (O'Brien and Leinfelder, 1935; Drescher and Benedict, I950; Van Buren and others, 1957; Bullock and Reeves, 1959; Moss, 1962; Silva, 1967; Smith, 1967). Haemangiomas are generally regarded as the primary orbital tumours of highest incidence and most favourable prognosis. We had five cavernous hemangiomas, none of the capillary variety, which proved to be well encapsulated and in every case excision resulted in a cure. Predominance was in young males with excellent preoperative vision, papilloedema, and striae, usually with no palpable mass or ophthalmoplegia and normal $x$-ray findings. Table II (overleaf) summarizes the salient features. In contrast the meningioma patients were mostly females presenting with marked visual loss (secondary to optic atrophy), external ophthalmoplegia, no palpable mass, and positive roentgenograms. The outcome of surgical excision was not very rewarding (Table III, overleaf).

Rhabdomyosarcoma remains the most common primary malignant orbital tumour in children and carries a very grave prognosis. Of interest in our group of three cases (age I I yrs, I $\frac{1}{2}$ yrs, and 3 days) is the last one; the tumour was present at birth and was excised at 3 days of age but recurred less than a year later.

Out of I,000 cases of orbital tumour seen at the registry of Ophthalmic Pathology (AFIP), Porterfield ( 1962 ) described 214 cases in children below 15 years of age. Rhabdomyosarcoma was the most frequent tumour and glioma the second. It is worthy of note that not a single case of glioma of the optic nerve was seen in this hospital and its clinics. Porterfield (1962) also stated that orbital metastases of neuroblastomas in children are much overrated in their frequency and presents three cases. This small series includes two such patients, 2 and 5 years of age, who both presented with exophthalmos and in both the origin was in the adrenal gland.

Sinus osteomas invading the orbit to produce exophthalmos are relatively rare and usually occur in the frontal or maxillary sinus. The single case recorded here is an ethmoidal osteoma. A related case is one of cementifying fibroma of the maxillary sinus.

Lesions of the lacrimal gland may or may not produce proptosis. Of six patients operated in our hospital, two had a benign mixed tumour, two had adenoid cystic carcinoma, one had tuberculous dacryoadenitis, and the remaining chronic nonspecific sclerosing 


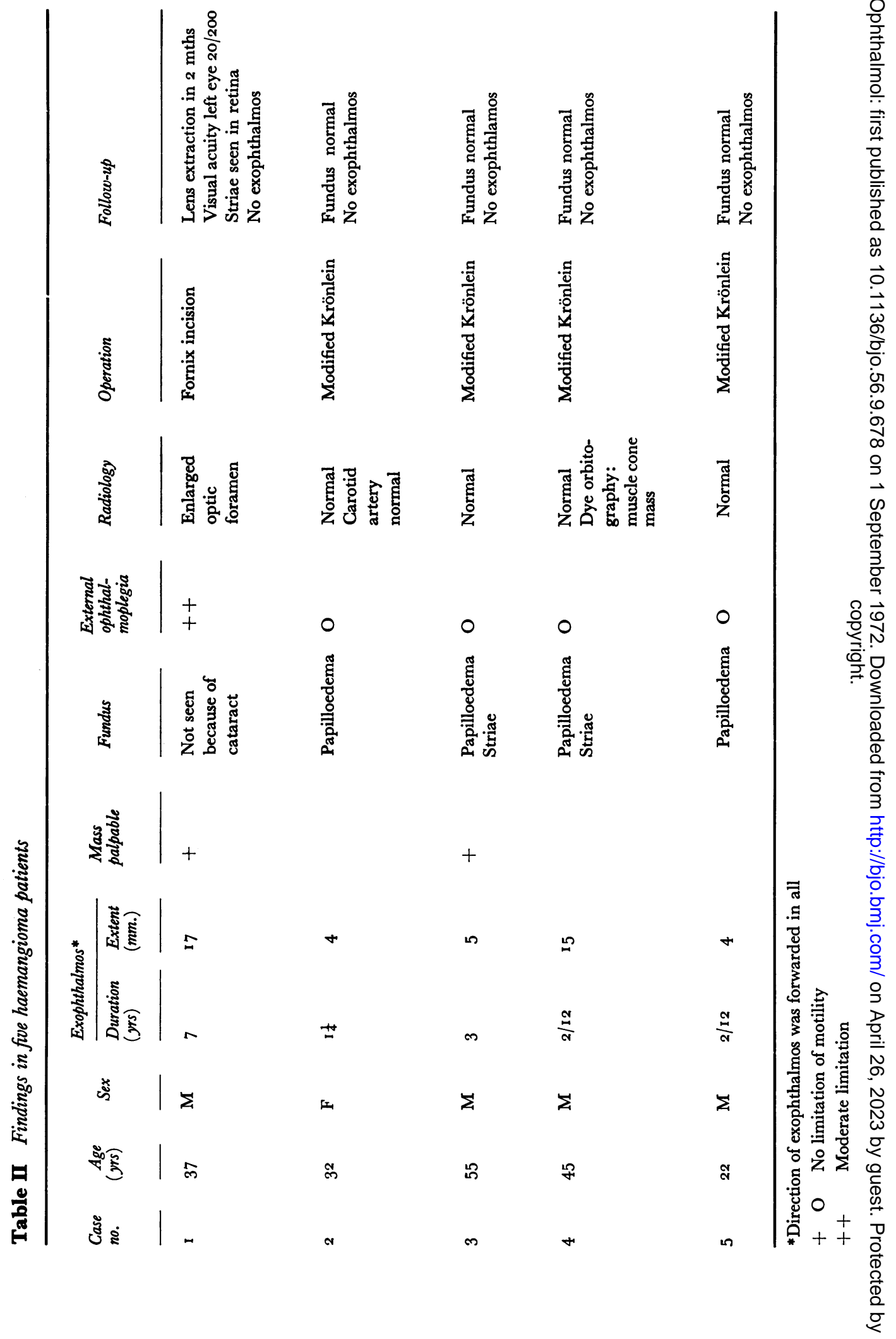




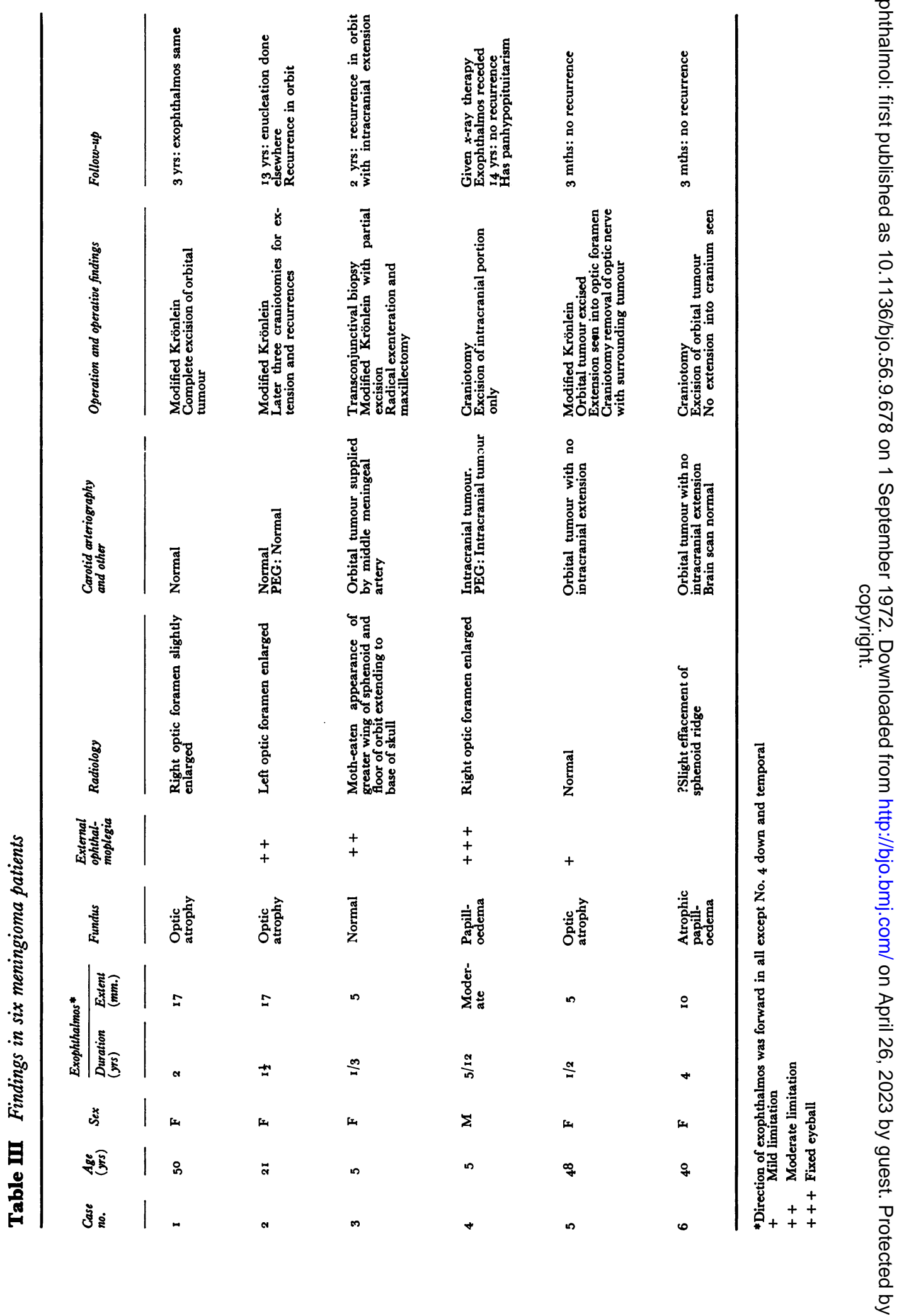


dacryoadenitis. Only the two with adenoid cystic carcinoma had exophthalmos, probably secondary to the more rapid growth of these lesions. Both patients had a recurrence after having refused exenteration.

The most common single cause of unilateral exophthalmos in our series was orbital cellulitis or abscess. The portal of entry was from an ethmoid sinusitis proven clinically and radiologically in seven patients, all below 15 years of age; two followed a conjunctival laceration, one a lid laceration, and one a pustule on the upper eyelid. In two, the portal of entry was not known. The remaining patient had a bacterial ulcer of the anterior staphyloma and developed a panophthalmitis followed immediately by orbital cellulitis; evisceration was performed. The organism cultured from the eviscerated material was Pseudomonas pyocyaneus. The other cultures revealed Staph. aureus coagulase-positive in four and Staph. albus coagulase-negative in three. In two patients the cultures were negative and in four no cultures were taken. Antibiotic therapy was effective in clearing the infection and reducing the exophthalmos in eleven patients; in three an abscess formed and had to be drained.

The endocrine group in our series is very small compared to other series in spite of an active endocrinology clinic, but is in agreement with the findings of O'Brien and Leinfelder (1935). Many of these cases were bilateral or had the other eye involved later and were excluded.

The group of "unknown" might be reduced further if we were to adopt a bold approach, as suggested by Mortada (1962). He reported on exploration of the orbit in nine patients presenting with unilateral exophthalmos and normal laboratory, radiological, and clinical findings including normal vision and fundus, and no palpable mass. He found haeman gioma to be the cause in seven patients. Most authors do not subscribe to this approact and do not operate unless there is a palpable mass or visual embarrassment related te fundus findings. We have subscribed to this approach so far.

Comparing our series to various reports in the literature, we find that the relative frequency of the various aetiologies of unilateral exophthalmos is very closely similar in several respects (Table IV, opposite). The neoplastic aetiology seems to rank first in all series in spite of the differing interests of the reporters: ophthalmic, otolaryngological, neurosurgical, or radiological. In the one series which does not show this preponderance (Schultz and others, I96I), the difference in favour of the endocrine group (three cases) is very small. The second most frequent cause was inflammatory or endocrine in that order.

\section{Summary}

The aetiology of unilateral exophthalmos was studied in 85 cases.

The conditions responsible for the exophthalmos were arranged into six groups: neoplastic, inflammatory, traumatic, endocrine, vascular, and unknown. The largest group was the neoplastic one, with meningioma and haemangioma heading the list. The most frequent single cause in this series was orbital cellulitis.

\section{References}

Baghdassarian, s. A., and zakharia, h. (i97i) Amer. F. Ophthal., 7i, io8i

Bogren, H., and tengroth, B. (i967) Clin. Radiol., 18, I93

Bullock, L. J., and Reeves, R. J. (1959) Amer. J. Roentgenol., 82, 290 


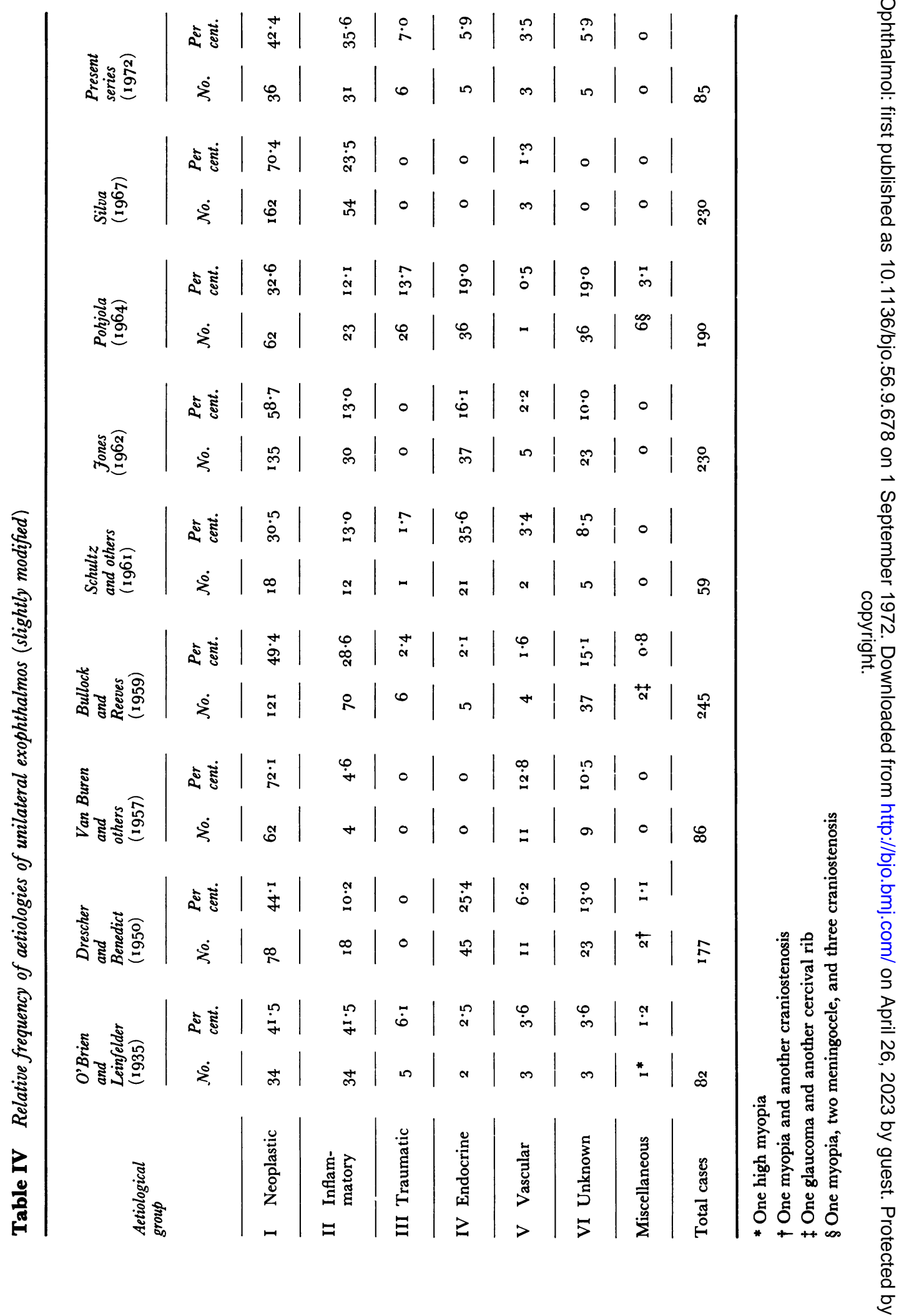


DANDY, W. E. (1941) “Orbital Tumours”. Oskas Piest, New York DRESGHER, E. P., and BENEDict, w. L. (1950) A.M.A. Arch. Ophthal., 44, 109 GITTER, K., MEYER, D., GoldBerg, R., and SARIN, L. K. (1968) Arch. Ophthal. (Chicago), 79, 370 JONES, I. (1962) Highlights of Ophthalmology-1962 series (U.S. ed.), 5, I KRAYENBÜHL, H. (1962) F. Neurosurg., 19, 289 MORTADA, A. (1962) Brit. F. Ophthal., 46, 369 моss, н. м. (1962) Amer. F. Ophthal., 54, 76r o'BRIEN, C. S., and LEINFELDER, P. J. (1935) Ibid., 18, 123

PALMER, B. W. (1965) Arch. Otolaryng., 82, 415

POHJOLA, s. (1964) Acta ophthal. (Kbh.), 42, 456

PORTERFIELD, J. (1962) Int. Ophthal. Clin., 2, 319

REese, A. B. (1964) In "Ocular and Adnexal Tumors", ed. M. Boniuk, p. 389. Mosby, St. Louis

SChUltz, R. O., Richards, R. D., and hamilton, h. E. (196I) Amer. F. Ophthal., 52, io silva, D. (1967) "Diagnosis of orbital tumours" in "Proc. II int. Symp. Plast. Reconstr. Surg. of

Eye and Adnexa", ed. B. Smith and J. M. Converse, pp. 108-1 15. Mosby, St. Louis Sмiтh, м. E. (1967) Int. Ophthal. Clin., 7, 9 I I

VAN BUREN, J. M., POPPEN, J. L., and hORRAX, G. (1957) Brain, 80, I 39 